\title{
CORRIGENDA
}

\section{CONTRIBUTION TO THE INTENSITY DISTRIBUTIONS OF THE MULTIPLET BANDS IN DIATOMIC MOLECULES II}

\author{
By \\ I. Kovács and A. Grandpierre \\ DEPARMENT OF ATOMIC PHYSICS, TECHNICAL UNIVERSITY, BUDAPEST
}

(Acta Phys. Hung., 43, pp. 319-345, 1977)

The line strengths of all $Q$-branches in column ${ }^{4} X(a)-{ }^{4} X(b)$ of Table $I$, in columns ${ }^{4} X(a)-{ }^{4} Y(b),{ }^{4} X(b)-{ }^{4} Y(a)$ of Table II, in column ${ }^{5} X(a)-{ }^{5} X(b)$ of Table III and in columns ${ }^{5} X(a)-{ }^{5} Y(b),{ }^{5} X(b)-{ }^{5} Y(a)$ of Table IV should be multiplied by 2 . 